\title{
Costs of asthma are correlated with severity: a 1-yr prospective study
}

\author{
P. Godard*, P. Chanez*, L. Siraudin*, N. Nicoloyannis*, G. Duru\#
}

Costs of asthma are correlated with severity: a 1-yr prospective study. P. Godard, P. Chanez, L. Siraudin, N. Nicoloyannis, G. Duru. C) ERS Journals Ltd 2002.

ABSTRACT: Asthma prevalence is increasing and asthma-related costs are likely to increase, but few studies have analysed the relationship of asthma costs and severity. The impact of severity on costs was quantified in a cohort of 318 asthmatic patients followed up prospectively for $1 \mathrm{yr}$.

Patients presenting with a broad range of severity of the disease (intermittent, mild persistent, moderate persistent, severe persistent) were recruited by chest physicians throughout France and treated for 1 yr according to customary clinical practice and following international guidelines. Severity, direct and indirect costs, and quality of life (QoL) were assessed. A multivariate analysis was conducted to relate factors contributing to the costs measured.

Mean direct costs for goods and services excluding hospitalization, numbers of consultations, supplementary examinations, and the use and cost of bronchodilators and corticosteroids, indirect costs of days lost from work, and adverse QoL parameters all increased significantly with increasing severity. This also applied to mean age, body weight, asthma duration, depression of forced expiratory volume in one second, and inhaled corticosteroid posology in the 234 patients completing the study. There was a significant relationship $(\mathrm{r}=\mathbf{0 . 6 1 4}, \mathrm{p}<\mathbf{0 . 0 0 1})$ between direct costs (hospitalization and cures were excluded) and three domains of the QoL questionnaire (mobility, pain and energy).

Overall costs of asthma (including individual direct costs, indirect costs, and intangible quality of life costs) are clearly related to severity. This is the first study in asthma to combine rigorous independent classification of grades of severity in statistically valid numbers of patients of grades receiving "real-world" treatment and followed-up prospectively for $1 \mathrm{yr}$. It allowed severity to be accurately related to direct, indirect and intangible costs of asthma. Quality of life explained a significant part of these costs. Eur Respir J 2002; 19: 61-67.
*Clinique des maladies respiratoires, Hôpital Arnaud de Villeneuve, Montpellier cedex and ${ }^{\#}$ Université UMR 58 23 Laboratoire d'analyse des systèmes de santé, Université CI, Villeurbanne, France.

Correspondence: P. Godard, Clinique des maladies respiratoires, Hôpital Arnaud de Villeneuve, Avenue Doyen Giraud, 34295 Montpellier cedex, France.

Fax: 33467521848

Keywords: Direct costs indirect costs

prospective study

quality of life

severity of asthma

Received: March 12001

Accepted after revision September 9 2001

The present study was supported by a research grant awarded to the Clinique des maladies respiratoires, Hôpital Arnaud de Villeneuve, Montpellier, France, by SmithKline Beecham Pharmaceuticals.
The burden of asthma has been assessed by several authors. It is clear that asthma prevalence is increasing [1] and that asthma-related costs are also likely to increase. For comparative purposes, it is therefore important to know the direct, indirect and intangible costs of asthma at a fixed time point. Costs could represent a useful outcome measure, in addition to quality of life (QoL) and other clinical measures, for monitoring interventional strategies in asthma care and assessing their cost-effectiveness [2,3]. Several pharmacoeconomic studies in asthma have been conducted in the USA [4-6] and Europe, including Spain [7], Switzerland [8], and elsewhere [9]. Most used a cross-sectional, retrospective, epidemiological approach

The concept of severity of asthma has long been used in clinical practice. In 1981, AAs [10] published a severity score that has since been used by several authors investigating the mechanisms of airway inflammation [11-13]. In the last decade, most national and international guidelines $[14,15]$ recommended its use for patient classification and treatment. Although the concept of severity is well accepted, few studies have analysed the relationship of costs of asthma to its severity. In 1998, SERRABATLLES et al. [7] showed that the costs varied substantially with severity of asthma, but this study was retrospective, only persistent asthma was evaluated, and patients were recruited from general practice only.

The main objective of the study reported here was to quantify the impact of severity on costs in a cohort of asthmatic patients followed up prospectively for $1 \mathrm{yr}$. This is the first analysis based on such a design [16]. The secondary objective was to identify parameters that are independently associated with costs of the disease.

\section{Methods}

\section{Patients}

Asthma patients of both sexes were consecutively enrolled by chest physicians, who were themselves chosen randomly to represent a range of professional 
settings (university, general, private centres) throughout France. Using spirometry and following international guidelines, the specialists evaluated asthma severity accurately at inclusion, and thus could recruit patients with different levels of severity. An age range of 16-44 yrs was chosen so that the cohort represented the active (not retired) population, and to avoid the likelihood of chronic obstructive pulmonary disease and comorbidities complicating the clinical picture [17]. Asthma was required to have been present for $>1 \mathrm{yr}$, and the diagnosis was confirmed using American Thoracic Society (ATS) criteria [14]. A minimum of $12 \%$ reversibility of airway obstruction had to have been documented for at least the previous year [18], and patients without airway obstruction had to have a history of bronchial hyperreactivity. Smoking was not an exclusion criterion.

\section{Severity assessment}

Asthma severity was evaluated on the basis of a history of brief episodic respiratory symptoms requiring $\beta_{2}$-agonists for relief or longer-lasting symptoms requiring systemic glucocorticosteroids (exacerbations), pulmonary function tests, and medication requirements, according to international guidelines. Case-report forms [19], used to validate an expert system for assessing severity [20], were completed by the chest physician for each patient at inclusion and at the end of follow-up.

Asthma severity was assessed twice, at inclusion in order to have a predefined number of patients and at the end of the 1-yr follow-up in order to assess it on a prospective basis.

Assessments of severity used in the final analyses were performed by an independent expert panel of physicians trained by one of the authors in line with international guidelines [14], and were classified as: 1) intermittent; 2) mild persistent; 3) moderate persistent; 4) severe persistent.

\section{Quality of life assessment}

The Nottingham Health Profile (NHP) used to assess QoL [21, 22] is a nonspecific, weighted questionnaire including 38 items in six domains, which was chosen because its French version has been validated [22], and because its use in a previous pharmacoeconomic study [21] enabled a calculation of the number of subjects needed in the present study to be made. The nondisease related nature of this instrument allows QoL comparisons between different chronic disorders.

\section{Pharmacoeconomic assessments}

Direct and indirect costs were evaluated prospectively throughout follow-up. Costs are expressed throughout in euros, followed in parentheses by the \$US equivalent, calculated using the mean of the June, July, and August 1998 exchange rates (6.0103
FFr/\$) [23] which was rounded off to 6.0 for the purposes of this paper. The exchange rate with the euro is constant (6.55).

Direct costs included: goods and services: primarycare physician and specialist consultations, supplementary examinations, medical procedures, physical therapy, home care, ambulance services, drugs and other medical supplies; hospitalizations (days), including emergency room visits; cures (days): a feature of medical management in France and elsewhere; a prescribed period spent with therapeutic intent at a health spa or similar establishment.

Indirect costs included: time lost from work (days), including hospitalization.

Unrelated asthma costs included: direct costs (in euros) and hospitalizations (days) not directly related to asthma.

\section{Study design}

Chest physicians entered successive patients who met the inclusion criteria into the study so as to achieve appropriate numbers in each stage of severity. Patients were treated for 1 yr (June 1996-July 1997) by their primary-care practitioners and chest physicians, using normal clinical practice. Specially trained investigators visited each patient at home on inclusion and after 3 and 9 months, and telephoned the patient each month between home visits.

At the end of follow-up, the specialist assessed severity and the QoL questionnaire was administered by the investigator at the final home visit (ninth month). Information on drug use from patient diaries was checked by the investigators during each home visit and telephone contact.

The study was approved by the institutional ethical committee. Written informed consent was obtained from each subject.

\section{Statistics}

At least 30 subjects were required in each severity stage group to ensure that the confidence interval of the cost means could be estimated with an accuracy of $36 \%$ of the mean, with a $5 \%$ confidence level, according to the hypothesis that the coefficient of variation of the costs was equal to unity (as shown in the study of LeBRUN et al. [21]). By the same hypothesis, this minimum sample size also ensured a discriminative power of $90 \%$ of the mean for $5 \%$ alpha and beta levels of significance.

For comparison of means, analysis of variance (ANOVA) and paired t-tests for independent samples were used when the sample sizes were large enough. Kruskall Wallis and Wilcoxon tests were used for sample sizes too small for parametric methods. A logistic regression was performed. The dependent variables were the total costs of asthma (hospitalizations and cures were excluded). The explanatory variables were the scores of the six domains of the NHP (mobility, pain, sleep, energy, social isolation, emotion). The results were adjusted to severity. 
Table 1.-Patient characteristics at baseline examination in relation to asthma severity

\begin{tabular}{lcccc}
\hline Parameter & \multicolumn{4}{c}{ Asthma stage } \\
\cline { 2 - 5 } & 1 & 2 & 3 & 4 \\
\hline Number & 32 & 78 & 91 & 33 \\
Age yrs & $32 \pm 9$ & $33 \pm 10$ & $37 \pm 10$ & $43 \pm 9$ \\
Gender female \% & 78 & 63 & 61 & 64 \\
Height cm & $165 \pm 8$ & $167 \pm 9$ & $166 \pm 10$ & $165 \pm 11$ \\
Weight Kg & $63 \pm 15$ & $67 \pm 14$ & $68 \pm 15$ & $76 \pm 16$ \\
Duration of asthma yrs & $16 \pm 11$ & $18 \pm 12$ & $21 \pm 12$ & $24 \pm 13$ \\
FEV1 \% predicted & $93 \pm 4$ & $91 \pm 4$ & $81 \pm 4$ & $59 \pm 7$ \\
Atopy* \% & 80 & 77 & 75 & 64 \\
Rhinitis \% & 72 & 68 & 64 & 67 \\
Current smokers \% & 19 & 19 & 21 & 12 \\
\hline
\end{tabular}

Data are presented as mean $\pm \mathrm{SD}$, unless otherwise stated. FEV1: forced expiratory volume in one second. *: atopy was defined by the presence of at least one positive skin-prick test.

Statistical tests and descriptive statistics were carried out using SPSS. The results are expressed as mean \pm SD, with the addition of median values where these may aid interpretation. The data were analysed in 1998.

\section{Results}

\section{Patient data}

Of 318 patients enrolled in the study by 134 chest physicians, $84(26.4 \%)$ were lost to follow-up. The only significant difference between this group and the remaining 234 patients was the nearly equal proportion of males $(52.4 \%)$ and females $(47.6 \%)$ in the former group, compared with the preponderance of females in the analysed group (64.5 versus $35.5 \%$ ).

There were 32, 78, 91 and 33 patients in severity categories 1, 2, 3, and 4, respectively. Several patient parameters were found to be correlated with asthma severity (table 1). Mean age was significantly different (ANOVA; $\mathrm{p}<0.0001$ ) between successive stages of asthma, and was positively correlated with severity. Females predominated $(65 \%)$ overall, but differences in sex ratio between stages were not significant. Mean body weight differed significantly between stages (Kruskal Wallis; $\mathrm{p}=0.003$ ) and increased with severity; duration of asthma also increased with severity (Kruskal Wallis; $\mathrm{p}=0.013$ ) and airflow impairment as represented by forced expiratory volume in one second (Kruskal Wallis; $\mathrm{p}=0.0001$ ). The number of peak expiratory flow rate (PEFR) records obtained increased with severity $(22,37,52$, and $52 \%)$.

In groups 1, 2, 3, and 4 respectively, 2 (16\%), 64 $(82 \%), 87(96 \%)$, and $30(90 \%)$ patients were treated with inhaled corticosteroids; mean \pm SD daily doses were $78 \pm 362 \mu \mathrm{g}, \quad 738 \pm 448 \mu \mathrm{g}, 1,258 \pm 518 \mu \mathrm{g}$, and $1,472 \pm 649 \mu \mathrm{g}$, and differences between all stages were significant (Kruskal Wallis; $\mathrm{p}<0.001$ ).

Concerning risk factors (table 1), atopy was slightly less frequent among patients with more severe disease than in other stages $(64 \%$ versus $80 \%) ; 67 \%$ of all patients had a history of rhinitis, but no correlation with severity was noted. The proportion of smokers ranged from $19-21 \%$ for stages $1-3$, but was somewhat lower $(12 \%)$ in stage 4 .

\section{Direct costs}

Mean direct costs for goods and services excluding hospitalization increased with severity and were significantly different between stages (Kruskal Wallis; $\mathrm{p}<0.001)$ (table 2). Mean costs associated with stages

Table 2. - Direct costs of asthma: mean costs of goods and services except hospitalization, in relation to asthma severity

\begin{tabular}{|c|c|c|c|c|}
\hline \multirow[t]{2}{*}{ Cost items } & \multicolumn{4}{|c|}{ Asthma stage } \\
\hline & 1 & 2 & 3 & 4 \\
\hline Consultations & $\begin{array}{c}50.76(55.50) \\
(57.05)\end{array}$ & $\begin{array}{c}89.60(97.96) \\
(200.29)\end{array}$ & $\begin{array}{c}127.13(138.99) \\
(142.74)\end{array}$ & $\begin{array}{c}262.46(286.95) \\
(327.80)\end{array}$ \\
\hline Supplementary examinations & $\begin{array}{c}42.76(46.76) \\
(48.75)\end{array}$ & $\begin{array}{l}73.24(80.08) \\
(62.44)\end{array}$ & $\begin{array}{c}94.36(103.17) \\
(98.46)\end{array}$ & $\begin{array}{c}236.49(258.56) \\
(323.68)\end{array}$ \\
\hline Medical procedures & $\begin{array}{c}10.43(11.40) \\
(44.43)\end{array}$ & $\begin{array}{c}11.86(12.97) \\
(56.57)\end{array}$ & $\begin{array}{c}13.89(15.19) \\
(67.40)\end{array}$ & $0.00(00.00)$ \\
\hline Physical therapy & $0.00(00.00)$ & $\begin{array}{c}8.40(9.19) \\
(335.62)\end{array}$ & $\begin{array}{c}17.49(19.13) \\
(465.01)\end{array}$ & $\begin{array}{c}53.04(57.99) \\
(1049.39)\end{array}$ \\
\hline Home care & $0.00(00.00)$ & $\begin{array}{c}0.09(0.11) \\
(0.87)\end{array}$ & $\begin{array}{c}2.25(2.47) \\
(11.47)\end{array}$ & $\begin{array}{c}131.32(143.57) \\
(715.12)\end{array}$ \\
\hline Ambulance services & $0.00(00.00)$ & $0.00(00.00)$ & $\begin{array}{c}29.81(32.60) \\
(133.21)\end{array}$ & $\begin{array}{c}151.29(165.41) \\
(362.28)\end{array}$ \\
\hline Drugs & $\begin{array}{c}152.60(166.84) \\
(128.66)\end{array}$ & $\begin{array}{c}500.26(546.93) \\
(392.23)\end{array}$ & $\begin{array}{c}901.51(985.60) \\
(541.25)\end{array}$ & $\begin{array}{c}1640.73(1793.75) \\
(1000.74)\end{array}$ \\
\hline Medical supplies & $\begin{array}{c}6.41(7.00) \\
(21.59)\end{array}$ & $\begin{array}{c}283.25(3.10) \\
(10.52)\end{array}$ & $\begin{array}{l}9.56(10.46) \\
(32.26)\end{array}$ & $\begin{array}{c}307.09(335.73) \\
(699.79)\end{array}$ \\
\hline Totals & $\begin{array}{c}262.97(287.50) \\
(180.87)\end{array}$ & $\begin{array}{c}686.31(750.32) \\
(499.54)\end{array}$ & $\begin{array}{c}1196.04(1307.59) \\
(685.44)\end{array}$ & $\begin{array}{c}2782.45(3041.20) \\
(2693.45)\end{array}$ \\
\hline
\end{tabular}

Data are presented as mean (US\$ equivalent) (SD in euros). 
Table 3. - Direct costs of asthma: distribution (\%) of mean costs of goods and services except hospitalization, in relation to asthma severity

\begin{tabular}{lrrrr}
\hline \multirow{2}{*}{ Cost items } & \multicolumn{4}{c}{ Asthma stage } \\
\cline { 2 - 5 } & 1 & 2 & \multicolumn{1}{c}{3} & 4 \\
\hline Drugs & 58.04 & 72.89 & 75.37 & 58.97 \\
Consultations & 19.30 & 13.06 & 10.63 & 9.43 \\
Supplementary examinations & 16.26 & 10.67 & 7.89 & 8.5 \\
Other* & 6.40 & 3.38 & 6.11 & 23.10 \\
\hline
\end{tabular}

*Includes medical procedures, physical therapy, home care, ambulance services, medical supplies.

1, 2, 3, and 4 were 263 euros (\$US288), 686 euros (\$US750), 1,196 euros (\$US1,308) and 2,782 euros (\$US3,042), respectively. The proportion of costs associated with consultations was similar $(\sim 11 \%)$ in stages 2, 3, and 4, but nearly twice as high $(19 \%)$ in stage 1 (table 3 ). Numbers of consultations with primary-care practitioners and specialists increased significantly with increasing severity (table 4) (Kruskal Wallis; $\mathrm{p}<0.001$ ), and the same was true of supplementary examinations. Drugs accounted for about three-quarters of the direct costs in stages 2 and 3 , but only $60 \%$ in the other stages. "Other" expenditure (medical procedures, physical therapy, home care, ambulance services, medical supplies) reached $23 \%$ in stage 4 (table 3 ).

Drug costs are summarized in table 5. Bronchodilators and corticosteroids predominated at all stages, and their use/cost increased significantly with increasing severity $(\mathrm{p}<0.001)$; the proportions in which they were used were, however, similar at each stage. Drugs such as immunostimulants, mucolytics, and antibiotics cost around 24 euros (\$US27), 43 euros (\$US47), 78 euros (\$US85) and 198 euros (\$US216) in groups 1-4, respectively, and accounted for $\sim 16,9,10$, and $12 \%$ of total drug costs. In addition, antihistamines and allergens cost 27 euros (\$US29), 43 euros (\$US47), 73 euros (\$US76), and 25 euros (\$US27), respectively.

Direct cost of hospitalization and cures (in days) are shown in figure 1 . No patients with stage 1 or 2 asthma were hospitalized, but mean periods in hospital were $>1$ day in stage 3 and $>6$ days with the most severe asthma cases $(1.24 \pm 5.42$ and $6.08 \pm$ 9.95). Overall, 30 patients were admitted, nine for $<24 \mathrm{~h}$. The pattern for cures was similar, with none of the less severe patients (stages 1 and 2) attending; mean attendance was $1.69 \pm 7.84$ days in stage 3 and $2.55 \pm 6.96$ days in stage 4 .

Direct expenditure not related to asthma differed

Table 4. - Direct costs of asthma: mean number of consultations with primary-care practitioners and chest physicians

\begin{tabular}{lcccc}
\hline Physicians & \multicolumn{5}{c}{ Asthma stage } \\
\cline { 2 - 5 } & 1 & 2 & 3 & 4 \\
\hline Primary care practitioners & $1.56 \pm 2.96(1)$ & $2.45 \pm 4.05(1)$ & $4.54 \pm 5.30(3)$ & $7.48 \pm 7.26(7)$ \\
Specialists & $2.41 \pm 2.76(1)$ & $3.22 \pm 5.00(2)$ & $3.66 \pm 3.37(3)$ & $7.70 \pm 12.57(5)$ \\
\hline
\end{tabular}

Data are presented as mean \pm SD (median).

Table 5. - Direct costs of asthma: mean costs of drugs in relation to asthma severity

\begin{tabular}{|c|c|c|c|c|}
\hline \multirow[t]{2}{*}{ Drugs } & \multicolumn{4}{|c|}{ Asthma stage } \\
\hline & 1 & 2 & 3 & 4 \\
\hline Bronchodilators & $\begin{array}{c}38.50(42.09) \\
(73.50)\end{array}$ & $\begin{array}{c}167.18(182.78) \\
(208.58)\end{array}$ & $\begin{array}{c}370.0(412.02) \\
(255.73)\end{array}$ & $\begin{array}{c}799.46(874.03) \\
(527.14)\end{array}$ \\
\hline Corticosteroids & $\begin{array}{c}48.175(52.67) \\
(75.70)\end{array}$ & $\begin{array}{r}208.51(00) \\
(224.84)\end{array}$ & $\begin{array}{r}355.76(00) \\
(272.91)\end{array}$ & $\begin{array}{r}601.47(00) \\
(349.20)\end{array}$ \\
\hline Antihistamines & $\begin{array}{c}21.13(22.77) \\
(232.82)\end{array}$ & $\begin{array}{r}39.80(00) \\
(458.15)\end{array}$ & $\begin{array}{c}67.15(73.41) \\
(589.99)\end{array}$ & $\begin{array}{c}25.05(27.40) \\
(260.60)\end{array}$ \\
\hline Antiallergics & $\begin{array}{l}15.10(16.51) \\
(97.32)\end{array}$ & $\begin{array}{l}38.24(41.82) \\
\quad(97.32)\end{array}$ & $\begin{array}{l}28.46(31.12) \\
\quad(82.02)\end{array}$ & $\begin{array}{l}16.72(18.29) \\
\quad(50.69)\end{array}$ \\
\hline Allergens & $\begin{array}{l}5.43(5.95) \\
(20.03)\end{array}$ & $\begin{array}{l}3.20(3.50) \\
(12.41)\end{array}$ & $\begin{array}{c}14.46(2.41) \\
\quad(11.12)\end{array}$ & $0.00(00.00)$ \\
\hline Immunostimulants & $\begin{array}{l}2.77(3.04) \\
(10.88)\end{array}$ & $\begin{array}{c}2.11(2.32) \\
\quad(8.82)\end{array}$ & $\begin{array}{c}3.16(3.46) \\
(12.03)\end{array}$ & $\begin{array}{c}2.67(2.93) \\
(8.63)\end{array}$ \\
\hline Mucolytics & $\begin{array}{c}3.87(4.24) \\
(6.58)\end{array}$ & $\begin{array}{c}8.17(8.94) \\
(23.44)\end{array}$ & $\begin{array}{c}8.16(8.92) \\
(15.95)\end{array}$ & $\begin{array}{c}26.30(28.75) \\
(31.16)\end{array}$ \\
\hline Antibiotics & $\begin{array}{c}17.60(19.24) \\
(21.10)\end{array}$ & $\begin{array}{c}33.00(336.01) \\
(46.93)\end{array}$ & $\begin{array}{c}66.59(72.80) \\
(121.19)\end{array}$ & $\begin{array}{c}169.02(184.78) \\
(518.07)\end{array}$ \\
\hline Totals & $\begin{array}{c}152.60(166.84) \\
(128.66)\end{array}$ & $\begin{array}{c}500.26(546.93) \\
(392.23)\end{array}$ & $\begin{array}{c}901.51(985.60) \\
(541.25)\end{array}$ & $\begin{array}{c}1640.73(1793.75) \\
(1000.74)\end{array}$ \\
\hline
\end{tabular}

Data are presented as mean (US\$ equivalent) (SD in euros). 


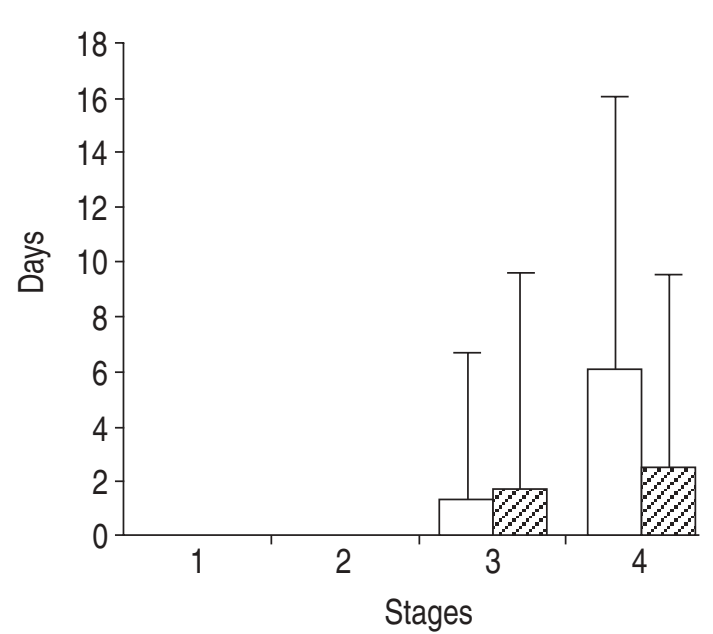

Fig. 1.-Direct costs of asthma: mean time spent in hospital ( $\square$ ) or cures $(\mathbb{Z})$, in relation to asthma severity.

little between stages and averaged 360 euros. Stage 4 was associated with significantly longer periods in hospital (1.66 days) than stages 1 and $2(0.12$ days).

\section{Indirect costs}

Days lost from work (table 6) represent the main indirect cost of asthma. Stages 1 and 2 were associated with hardly any days lost, but mean days lost increased with stages 3 and 4 . The cost increase with increasing severity between stages 1-2 and 3-4 was highly significant (Kruskal Wallis $\mathrm{p}<0.001$ ).

\section{Intangible costs}

QoL scores were significantly different between each stage for all domains (Kruskal Wallis; $p<0.001$ ); however, discriminant factor analysis did not indicate a strong inverse relationship between QoL and severity (fig. 2). As a whole, $20 \%$ of the variance was explained by the first, second and fourth domains (mobility, pain, and energy respectively) of the NHP. Adjusted for severity, the linear regression was significant $(\mathrm{r}=0.614 ; \mathrm{p}<0.001)$ between the direct costs and the 1, 2, and 4 domains of the NHP.

Table 6. - Indirect costs of asthma: mean time lost from work in relation to asthma severity

\begin{tabular}{lcccc}
\hline Work & \multicolumn{5}{c}{ Asthma stage } \\
\cline { 2 - 5 } $\begin{array}{l}\text { time lost } \\
\text { through }\end{array}$ & 1 & 2 & 3 & 4 \\
asthma & & & & \\
\hline $\begin{array}{l}\text { Mean } \\
\text { period }\end{array}$ & $0.03 \pm 0.18$ & $0.58 \pm 2.74$ & $5.38 \pm 21.44$ & $8.59 \pm 15.85$ \\
\hline
\end{tabular}

Data are presented as mean days \pm SD.

\section{Discussion}

This study has shown that the overall cost of asthma is as clearly related to severity as the individual direct costs, indirect costs, and intangible costs related to QoL. Data collection was especially rigorous, being prospective, regular and supervised by trained investigators. In particular, the evaluation of asthma severity at the end of a $1-y r$ prospective follow-up was based not only on international recommendations, but also on a review of all patient files by an independent panel of physicians. The correlations found between asthma severity and both lung function and inhaled corticosteroid daily dose have retrospectively demonstrated the practical consistency of this classification method. Asthma severity is difficult to assess, particularly if international recommendations have not been fully understood, as stressed by Doerschug et al. [24]. Confining the study to patients between 16-44 yrs ensured a reasonably homogeneous cohort. Health problems affecting elderly people are likely to be more numerous and serious, and attended by the effects of multiple drug therapy $[25,26]$.

The patients in the present study were treated according to best practice by their primary-care practitioners and chest physicians who followed international recommendations (as shown by the agreement between the severity and the amount of inhaled corticosteroid used), and they were also assessed expertly and regularly. Patients regularly measured their PEFR, and the rate of self-monitoring in relation to severity compared well with other published figures [27].

The present study was not designed to study asthma control, partly because no published, validated control score is yet available (though the patients who were not admitted to hospital during the 1-yr followup could be considered as being well controlled). However, effective asthma control reduces costs, particularly by decreasing hospitalization $[6,9,28]$. WeIss et al. [5] recently pointed out that, "The numbers of hospitalizations will fall when national treatment guidelines are followed," and costs of asthma are, "largely due to uncontrolled disease, indicating that current therapies are either underused or misused in practice" [9]. The early and adequate use of inhaled corticosteroids, in line with National Institute of Health (NIH)/National Heart, Lung and Blood Institute (NHLBI) recommendations, have a key role in preventing disease progression and helping to prevent or curtail hospitalization.

To conclude, the study reported here is the first in asthma to combine several key features. It involved a rigorous independent classification of grades of severity, and took into account current international management guidelines. Statistically valid numbers of patients with asthma of all stages of severity who were receiving "real-world" treatment were followed up prospectively for $1 \mathrm{yr}$, allowing for the correlation of severity with direct, indirect and intangible costs of asthma. The concept of irreducible costs should be a prospect for future studies on pharmacoeconomic research in asthma. 

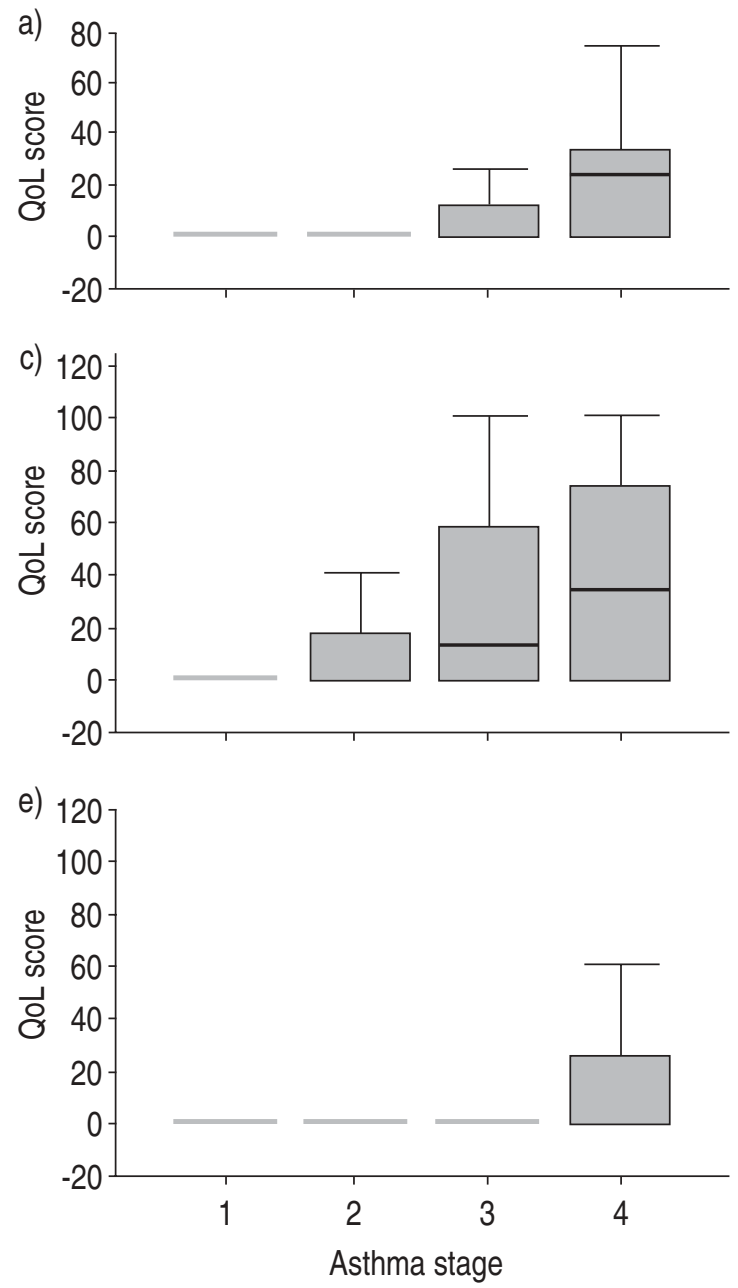

b)

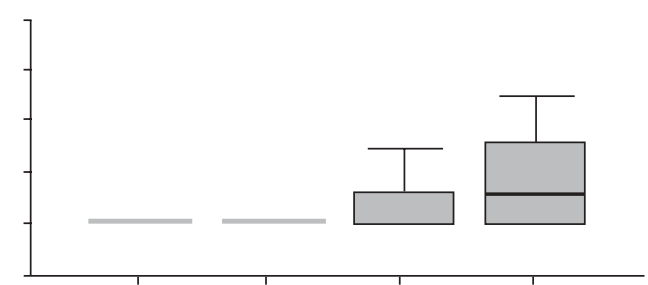

d)

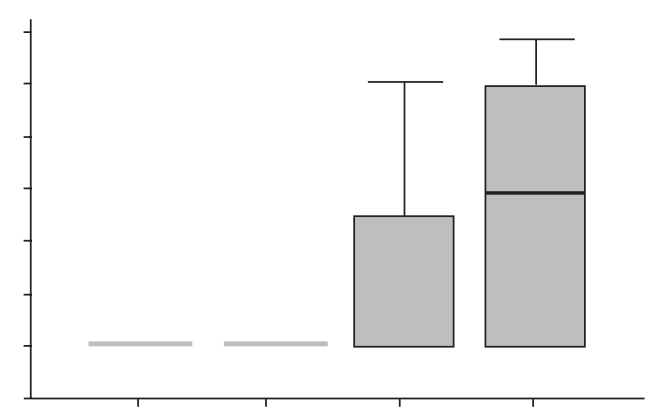

f)

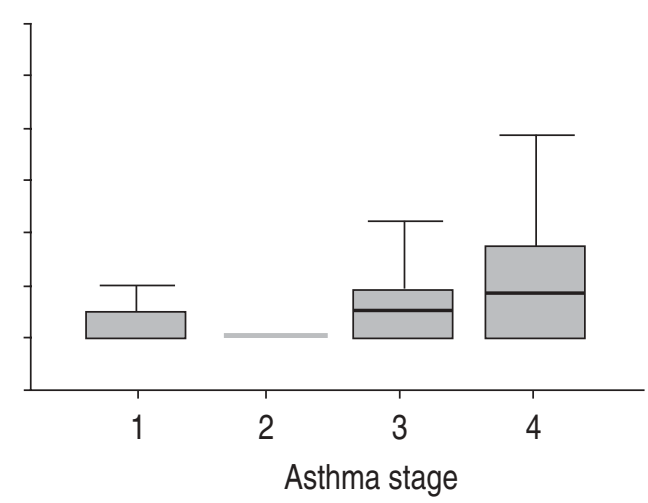

Fig. 2.-Quality of life (QoL) and asthma: QoL scores for the six domains: a) mobility; b) pain; c) sleep; d) energy; e) social isolation; f) emotional reaction, of the Nottingham Health Profile (French version, BUCQUET and CondON [22]), in relation to asthma severity. Scores increased significantly with severity for all domains (Kruskal Wallis; $\mathrm{p}<0.001$ ).

\section{References}

1. Upton MN, McConnachie A, McSharry $\mathrm{C}$, et al. Intergenerational 20 year trends in the prevalence of asthma and hay fever in adults: the Midspan family study surveys of parents and offspring. BMJ 2000; 321: 88-92.

2. Watkins KD. Asthma outcome measures. J Med Syst 1999; 23: 261-268.

3. Gibson PG. Monitoring the patient with asthma: an evidence-based approach. J Allergy Clin Immunol 2000; 106: 17-26.

4. Weiss KB, Gergen PJ, Hodgson TA. An economic evaluation of asthma in the United States. $N$ Engl J Med 1992; 326: 862-866.

5. Weiss KB, Sullivan SD, Lyttle CS. Trends in the cost of illness for asthma in the United States, 1985-1994. J Allergy Clin Immunol 2000; 106: 493-499.

6. Smith DH, Malone DC, Lawson KA, Okamoto LJ, Battista C, Saunders WB. A national estimate of the economic costs of asthma. Am J Respir Crit Care Med 1997; 156: 787-793.

7. Serra-Batlles J, Plaza V, Morejon E, Comella A,
Brugues J. Costs of asthma according to the degree of severity. Eur Respir J 1998; 12: 1322-1326.

8. Szucs TD, Anderhub H, Rutishauser M. The economic burden of asthma: direct and indirect costs in Switzerland. Eur Respir J 1999; 13: 281-286.

9. Barnes PJ, Jonsson B, Klim JB. The costs of asthma. Eur Respir J 1996; 4: 636-642.

10. Aas K. Heterogeneity of bronchial asthma. Subpopulations - or different stages of the disease. Allergy 1981; 36: 3-14.

11. Cluzel M, Damon M, Chanez P, et al. Enhanced alveolar cell luminol-dependent chemiluminescence in asthma. J Allergy Clin Immunol 1987; 80: 195-201.

12. Bousquet J, Chanez P, Lacoste JY, et al. Eosinophilic inflammation in asthma. $N$ Engl J Med 1990; 323: 1033-1039.

13. Bentley AM, Menz G, Storz C, et al. Identification of $\mathrm{T}$ lymphocytes, macrophages, and activated eosinophils in the bronchial mucosa in intrinsic asthma. Relationship to symptoms and bronchial responsiveness. Am Rev Respir Dis 1992; 146: 500-506.

14. National Institutes of Health. Expert Panel Report 2: Guidelines for the diagnosis and management of 
asthma. NIH publication number 97-4051. Bethesda: NIH/National Heart, Lung and Blood Institute, 1997.

15. The British Thoracic Society, The National Asthma Campaign, The Royal College of Physicians of London, et al. British Guidelines on Asthma Management. Thorax 1997; 52: Suppl. 2, S1-S21.

16. Mellis CM, Peat JK, Woolcock AJ. The cost of asthma: can it be reduced? Pharmacoeconomics 1993; 3: 205-219.

17. Jacobson L, Hertzman P, Lofdahl CG, Skoogh BE, Lindgren $\mathrm{B}$. The economic impact of asthma and chronic obstructive pulmonary disease (COPD) in Sweden in 1980 and 1991. Respir Med 2000; 9: $247-$ 255.

18. Crapo RO. Pulmonary function testing. $N$ Engl J Med 1994; 331: 25-30.

19. Godard P, Chanez P, Bousquet J, Demoly P, Pujol JL, Michel FB. Abrégé d'asthmologie. Paris, Masson, 1999.

20. Rédier H, Daures JP, Michel C, et al. Assessment of the severity of asthma by an expert system. Description and evaluation. Am J Respir Crit Care Med 1995; 151: $345-352$.

21. Lebrun T, Sailly JC, Leclercq A, Chocoye A, Requin B. Les répercussions fonctionnelles, professionnelles, et en terme de recours au soins, dans l'asthme chronique. Rev Mal Resp 1994; 11: 369-378.
22. Bucquet D, Condon S. Adaptation en français du Nottingham Health Profile (NHP) et caractéristiques opératoires de la version française. Montpellier, INSERM-CJF 88-12, March 1990.

23. Federal Reserve Bank. Foreign exchange rates for the month ending August 1998. Federal Reserve Statistical Release September 1, 1998.

24. Doerschug KC, Peterson MW, Dayton CS, Kline JN. Asthma guidelines: an assessment of physician understanding and practice. Am J Respir Crit Care Med 1999; 159: 1735-1741.

25. Plaza V, Serra-Batlles J, Ferrer M, Morejon E. Quality of life and economic features in elderly asthmatics. Respiration 2000; 67: 65-70.

26. Wong CA, Walsh LJ, Smith CJ, et al. Inhaled corticosteroid use and bone-mineral density in patients with asthma. Lancet 2000; 355: 1399-1403.

27. Cote J, Cartier A, Malo JL, Rouleau M, Boulet LP. Compliance with peak expiratory flow monitoring in home management of asthma. Chest 1998; 113: 968972.

28. Groban D, Evans RM, Edgren B, et al. Clinical benefits and cost reduction associated with a comprehensive asthma management program at a managed care organization. Dis Man Health Outcomes 1998; 4: 93-100. 